\title{
TRABALHO NOTURNO E A REPERCUSSÃO NA SAÚDE DOS ENFERMEIROS
}

\author{
Night shift and the repercussion in nurses' health \\ El trabajo nocturno y su repercusión en la salud de los enfermeros
}

Rosângela Marion da Silva ${ }^{1}$
Maria Isabel Sampaio Carmagnani ${ }^{4}$

\author{
Tânia Solange Bosi de Souza Magnago 3 \\ Francine Cassol Prestes 6
}

\section{RESUMO}

0 trabalho de enfermagem é organizado em turnos para prestar cuidado ininterrupto e atender a demanda da população por serviços de saúde. Trata-se de uma pesquisa descritiva e exploratória, realizada no período de março de 2008 no Hospital Universitário de Santa Maria/RS, Brasil. 0 objetivo é apresentar e discutir as alterações na saúde percebidas por enfermeiros do período noturno. Os participantes foram 42 enfermeiros submetidos a entrevista cujos dados foram analisados segundo a análise temática. Os resultados evidenciaram que 27 enfermeiros percebem alterações na saúde como a má qualidade no sono/repouso, o cansaço/desgaste, entre outras. Por outro lado, há a conveniência de trabalhar no período noturno para continuar os estudos ou a possibilidade de conciliar o segundo emprego. Pôde-se concluir que é necessário uma compreensão do trabalhador sobre os limites do seu corpo para que a realização da atividade não interfira no processo saúde-doença e não comprometa a assistência prestada.

Palavras-chave: Trabalho Noturno. Saúde do Trabalhador. Tolerância ao Trabalho Programado. Enfermagem.

\begin{abstract}
Nursing work is organized into shits to provide uninterrupted care and fulfill the demand of the population for health services. It is a descriptive and exploratory research, conducted in the period of March 2008 in the University Hospital of Santa Maria/RS, Brazil. The objective is to present and discuss the changes in health perceived by nurses in the night shitt. The participants were 42 nurses submitted to interviews, whose data were analyzed according to the theme analysis. The results confirmed that 27 nurses perceive changes in health: sleepiness/rest, tiredness/burnout among others. On the other hand, there is the convenience of working in the night shitt in order to continue with studies and the possibility of conciliating a second job. In conclusion is necessary a comprehension of the workers on their bodies limits to perform an activity which does not interfere with the process health-sickness and does not compromise the service provided.
\end{abstract}

Keywords: Night work. Occupational health. Work schedule tolerante. Nursing.

\section{Resumen}

El trabajo de enfermería está organizado en turnos para prestar cuidado ininterrumpido y atender a la demanda de la población por servicios de salud. Se trata de una investigación descriptiva y exploratoria, realizada en marzo de 2008 en el Hospital Universitário de Santa Maria/RS, Brasil. El objetivo es presentar y discutir las alteraciones en la salud percibidas por enfermeros del periodo nocturno. Los participantes fueron 42 enfermeros sometidos a una entrevista cuyos datos fueron analizados según el análisis temático. Los resultados evidenciaron que 27 enfermeros perciben alteraciones en la salud como la mala calidad en el sueño/ reposo o el cansancio/desgaste, entre otras. Por otra parte, existe la conveniencia de trabajar en el periodo nocturno para continuar los estudios o la posibilidad de conciliar un segundo empleo. En conclusión, se necesita que el trabajador alcance una comprensión de los límites de su cuerpo, para que la realización de la actividad no interfiera en el proceso salud-enfermedad y no perjudique la asistencia prestada.

Palabras clave: Trabajo nocturno. Salud laboral. Tolerancia al trabajo programado. Enfermagem.

\footnotetext{
${ }^{1}$ Enfermeira do Hospital Universitário de Santa Maria. Mestre em Enfermagem. Membro do Grupo de Estudos e Pesquisa "Trabalho, Saúde, Educação e Enfermagem" da Universidade Federal de Santa Maria (UFSM), Santa Maria- RS. Brasil. rosangelamarion@ smail.ufsm.br, ${ }^{2}$ Enfermeira. Professora Doutora Associada do Departamento de Enfermagem da UFSM. Membro do Grupo de Estudos e Pesquisa "Trabalho, Saúde, Educação e Enfermagem" da UFSM. Coordenadora da Linha de Pesquisa Saúde do Trabalhador, Santa Maria-RS. Brasil. carmembeck@ gmail.com, ${ }^{3}$ Enfermeira. Professora Doutora Adjunta do Departamento de Enfermagem da UFSM. Membro do Grupo de Estudos e Pesquisa "Trabalho, Saúde, Educação e Enfermagem" da Universidade Federal de Santa Maria-RS. Brasil. tmagnago@ terra.com.br," Enfermeira. Professora Doutora Adjunta do Departamento de Enfermagem da UNIFESP, disciplina de Administração Aplicada a Enfermagem, Diretora de Enfermagem do Hospital São Paulo. São PauloSP. Brasil. carmagnani@ unifesp.br, ${ }^{5}$ Enfermeira. Mestranda em Enfermagem pelo PPGEnf UFSM. Professora Substituta do Departamento de Enfermagem da UFSM. Membro do Grupo de Estudos e Pesquisa "Trabalho, Saúde, Educação e Enfermagem" da Universidade Federal de Santa Maria. Santa Maria-RS. Brasil. E-mail: jupetritavares@ gmail.com, Enfermeira. Mestranda em Enfermagem pelo PPGEnf da UFSM. Membro do Grupo de Estudos e Pesquisa "Trabalho, Saúde, Educação e Enfermagem" da UFS. Santa MariaRS. Brasil. francinecasso@ gmail.com
} 


\section{INTRODUÇÃO}

As transformações ocorridas no mundo do trabalho têm repercutido na saúde dos trabalhadores de forma incisiva. A incorporação de novas tecnologias, adicionadas a um complexo conjunto de inovações organizacionais tem interferido nas condições e as relações de trabalho. A intensificação laboral é elemento característico da atual fase do capitalismo o que implica em consumo de energias físicas e espirituais dos trabalhadores. ${ }^{1}$

Essas transformações podem desencadear uma desarmonia na relação homem-trabalho, o que possibilita a ocorrência de alterações na saúde do trabalhador em decorrência do processo de trabalho que precisa ser reorganizado, de forma a atender as necessidades de cada profissão. Na área da saúde, em especial na enfermagem, uma das formas de organizar o trabalho foi implantar o trabalho noturno com o intuito de prestar cuidado ininterrupto e atender a demanda da população pelos serviços de saúde.

Este turno de trabalho não é uma invenção da era industrial uma vez que já existia desde que os homens se organizaram em cidades e estados. ${ }^{2}$ Porém, a preocupação com o trabalho noturno é tema atual e, cada vez mais, vem sendo estudado por pesquisadores de diversas áreas.

As consequências da realização do trabalho no período noturno na saúde do trabalhador manifestam-se como alterações do equilíbrio biológico, dos hábitos alimentares e do sono, na perda de atenção, na acumulação de erros, no estado de animo e na vida familiar e social. Essa particularidade requer atenção dos profissionais que têm a responsabilidade de dimensionar os recursos humanos em relação às atividades de enfermagem. ${ }^{3}$

As alterações ocorrem porque 0 trabalho realizado no noturno provoca situações que exigem adaptação do trabalhador, uma vez que esse experimenta uma inversão do ciclo sono-vigília, ou seja, ocorre um desordenamento do ritmo circadiano porque o trabalhador realiza a atividade no momento em que o organismo se prepara para o descanso. Os ritmos cicardianos são alterações regulares, com características mentais e físicas, que ocorrem no curso de um dia, e muitos deles são controlados pelo relógio biológico localizado no hipotálamo. ${ }^{4}$ Os ritmos circadianos são ritmos biológicos que variam em torno de 24 horas e podem ser eventos bioquímicos, fisiológicos ou comportamentais. Estes ritmos são controlados por sincronizadores externos como a luz, a alimentação, entre outros, mas também persistem sem estas pistas ambientais, 0 que os caracteriza como ritmos gerados endogenamente. ${ }^{5}$

0 processo de trabalho do enfermeiro no período noturno possibilita, em muitas situações, atuar com autonomia, o que pode ser um fator que contribui para a satisfação no trabalho. Por outro lado, no que tange às normas organizacionais, a dificuldade em participar de espaços promovidos pela instituição no período diurno pode ser considerada desgastante e angustiante para o trabalhador do noturno, 0 que pode favorecer a insatisfação com relação a esse componente do trabalho. ${ }^{6}$

Em virtude da complexidade do processo de trabalho do enfermeiro, cuja atividade exige concentração, estado de alerta, rapidez, qualidade na execução de tarefas previstas e imprevistas, gerenciamento do turno de trabalho, supervisão do trabalho de enfermagem entre outras tarefas que determinam a organização sistemática do trabalho, são relevantes pesquisas que buscam identificar as repercussões na saúde percebidas pelos enfermeiros decorrentes da realização da atividade no período noturno. Tal proposição pode contribuir com a eleição de medidas preventivas que poderão auxiliar no desempenho das atividades, na qualidade de vida e na assistência prestada.

Este ar tigo tem como objetivo apresentar e discutir as alterações na saúde percebidas por enfermeiros de um Hospital Universitário decorrente da realização do trabalho no período noturno.

\section{METODOLOGIA}

Este estudo caracteriza-se por ser uma investigação de campo, descritiva com abordagem qualitativa. Foi realizado no Hospital Universitário de Santa Maria, hospital-escola Porte IV localizado na Região Sul do Brasil. Esse hospital é referência de alta complexidade para 45 cidades da região centro-oeste do Estado do Rio Grande do Sul, e os atendimentos prestados à comunidade são realizados em salas de atendimento de emergência, localizadas no pronto atendimento adulto e infantil, salas do centro cirúrgico, salas de ambulatório, sala de recuperação anestésica e unidades de internação. Os trabalhadores de enfermagem executam suas atividades nos turnos da manhã - das $7 \mathrm{~h}$ às $13 \mathrm{~h}$; tarde - das $13 \mathrm{~h}$ às $19 \mathrm{~h}$; e noite - das $19 \mathrm{~h}$ às $7 \mathrm{~h}$ do dia seguinte.

Os dados foram coletados com a população de 66 enfermeiros em março de 2008. Os critérios de inclusão: atuar há, pelo menos, um ano no serviço noturno na instituição, pertencer ao quadro permanente e estar em efetivo exercício no período da coleta de dados.

Os enfermeiros foram informados sobre os objetivos da pesquisa e garantia do anonimato. Após os esclarecimentos, foram orientados a realizar a leitura do Termo de Consentimento Livre e Esclarecido e posterior assinatura.

A técnica de coleta de dados utilizada foi a entrevista semiestruturada que foi gravada em microgravador digital MP3 player após a autorização do entrevistado. A mesma foi realizada individualmente, em data e horário previamente combinados com o enfermeiro em sua unidade de trabalho. Após, os fragmentos foram transcritos na íntegra.

Os dados foram submetidos à análise temática, ${ }^{7}$ que constitui uma das técnicas que se prestam à investigação qualitativa, na qual se classificam os diversos elementos da comunicação a partir de leituras que permitem identificar 0 
Trabalho noturno e a sáude dos enfermeiros.

sentido mediante 0 ordenamento das ideias expressas pelos entrevistados. Essa categorização é um procedimento sistemático que permite descobrir os núcleos de sentidos expressos nas falas dos entrevistados.

Para preservar a identidade dos enfermeiros, foi atribuída a letra $\mathrm{E}$ (Enfermeiro) seguida do número de ordem da realização das entrevistas (E1, E2, E3,...).

A pesquisa atendeu aos princípios da Resolução 196/ 96 do Conselho Nacional em Saúde ${ }^{8}$ e foi submetida ao Comitê de Ética e Pesquisa da instituição da Universidade Federal de Santa Maria. Obteve parecer favorável do Certificado de Apresentação para Apreciação Ética (CAAE) sob n ${ }^{\circ}$ 0012.0.243.000-08 em 12 de fevereiro de 2008, número do processo 23081.000770/2008-61.

\section{RESULTADOS E DISCUSSÃO}

A amostra deste estudo foi composta por 42 enfermeiros distribuídos pelas diferentes unidades de trabalho: Centro Obstétrico, Tocoginecológica, Clínica Cirúrgica, Clínica Médica I, Clínica Médica II, Pediatria,
Tratamento Intensivo Pediátrica, Pronto Atendimento Adulto, Pronto Atendimento Infantil, Tratamento Intensivo Neonatal, Sala de Recuperação Anestésica, Bloco Cirúrgico, Centro de Material e Esterilização, Centro de Tratamento à Criança com Câncer e Centro de Tratamento Hemato-oncológico, Unidade de Internação Psiquiátrica e para dependentes químicos.

A maioria dos enfermeiros é do sexo feminino $(90,48 \%)$, com faixa etária maior que 41 anos de idade $(64,28 \%)$, estado civil casado ou com companheiro $(64,29 \%)$, com filhos $(80,96 \%)$ e que optaram pelo trabalho noturno $(90,48 \%)$.

Dos 42 enfermeiros que participaram deste estudo, 27 $(57,14 \%)$ percebem uma ou mais alterações na saúde decorrente da realização do trabalho no período noturno. Por meio da análise dos fragmentos identificaram-se relatos de alterações físicas, psíquicas e fisiológicas como o cansaçol desgaste, a má qualidade no sono/repouso, o ganho ponderal, 0 mal-estar gástrico entre outras, 0 que se entende como fatores que podem comprometer a qualidade de vida desses trabalhadores.

Tabela 1- Alterações percebidas por enfermeiros que atuam no período noturno. HUSM,

\begin{tabular}{lc}
\hline ALTERAÇÃO & FREQUÊNCIA \\
\hline Cansaço/desgaste & 6 \\
Má qualidade no sono/repouso & 5 \\
Ganho ponderal & 5 \\
\hline Mal-estar gástrico & 4 \\
\hline Impossibilidade da prática de atividade física & 2 \\
\hline Hipertensão & 2 \\
\hline Estresse & 1 \\
\hline Envelhecimento & 1 \\
\hline Lombalgia & 1 \\
\hline TOTAL & $\mathbf{2 7}$ \\
\hline
\end{tabular}

Santa Maria, RS, 2008.

Observa-se na Tabela 1 que cinco enfermeiros referiram possuir má qualidade do sono/repouso como uma das principais alterações percebidas. Tal alteração pode interferir em outros fatores como o contexto social e familiar, o que sugere 0 comprometimento do estado físico, emocional e comportamental desses trabalhadores. As falas a seguir evidenciam essa situação:

[...] no outro dia a pessoa fica mais estressada, tem alteração de humor, tu chega a ficar, no outro dia, uma bomba [...] qualquer coisa, pronto!(E48). $[\ldots]$ diminuiu minha energia [...] meu humor [...] estou diferente (E28).

0 sono perdido, muitas vezes, não consegue ser recompensado pela pessoa que executa atividades no período noturno. Quando persistente e com efeito cumulativo, o sono pode desencadear a diminuição da capacidade mental e 0 cansaço físico inevitável. Este último foi evidenciado pela maioria dos trabalhadores, como pode-se observar na Tabela 1. Além disso, a privação do sono é fator que pode comprometer tanto a saúde do trabalhador quanto a 


\section{Trabalho noturno e a sáude dos enfermeiros.}

assistência prestada, pois reduz o estado de alerta e a atenção do trabalhador.

0 sono é caracterizado por uma diminuição da consciência, redução dos movimentos musculares esqueléticos e lentificação do metabolismo. Tem função restauradora essencial e importante papel na consolidação da memória. Bebidas cafeinadas, certas drogas, medicamentos e descongestionantes nasais estimulam algumas partes do cérebro e causam insônia. A sonolência é causada pela liberação, ao anoitecer, do hormônio melatonina pela glândula pineal. Essa glândula tem sua função regulada pela luminosidade do dia. ${ }^{4}$ Dessa forma, ao ser liberado na corrente sanguínea, esse hormônio, invariavelmente, induz o sono.

Pesquisa demonstrou que, dos 53 trabalhadores de enfermagem que atuavam no noturno, 35,8\% consideravam este turno de trabalho responsável por transtornos do sono e $15,1 \%$ consideravam que o trabalho realizado neste horário agravava estes transtornos. ${ }^{9}$

Quando se trata de descanso ou sono diurno do trabalhador do noturno, alguns fatores característicos do horário diurno devem ser levados em consideração, como a luminosidade, 0 to que do telefone, as conversas, o cuidado com os filhos, os sons externos ao ambiente, buzinas mais frequentes, ruídos de limpeza de carros ou casa, maior movimentação de carros, entre outros, os quais podem comprometer 0 descanso desse trabalhador. Autor considera que 0 sono diurno não possui a mesma qualidade e capacidade reparadora do sono noturno, o que resulta em diminuição da capacidade produtiva do trabalhador que executa atividades no noturno devido ao débito de sono cumulativo. ${ }^{10}$

0 ganho ponderal e o mal-estar gástrico, referidos por cinco e quatro enfermeiros, respectivamente, foram relacionados aos maus hábitos alimentares, ao lanche coletivo utilizado como estratégia para inibir o sono, conforme fragmentos a seguir:

[...] nunca fui uma pessoa magra, mas o eu percebo que, com o trabalho a noite, como passar dos anos, foi se acumulando um sobrepeso e que nunca foi diminuindo [...] e eu atribuo a maus hábitos alimentares e descuido com a qualidade da a limentação em função da coletividade no plantão que estimula se alimentar cada vez mais com a intenção de se manter acordado. Todo mundo faz um lanche, depois toma um cafezinho e assim vai[ ...] (E45).

[...] aumento de peso, porque tu come a noite inteira. São 10 ou 11 plantões por mês que eu estaria dormindo e tu come [...] (EOg).

[...] eu tive gastrite bem severa. Estou fazendo tratamento (E32).
Os maus hábitos alimentares e o descuido com a qualidade da alimentação podem estar relacionados à ingestão de alimentos de fácil preparo, com baixa qualidade nutricional, 0 que possibilita 0 aparecimento de transtornos digestivos. Pesquisador que estudou as alterações psicofisiológicas em trabalhadores de enfermagem que atuavam em uma Unidade de Terapia Intensiva no serviço noturno presenciou, durante os plantões, a ingestão de pizza, hambúrguer, salgadinhos, bolos de chocolate e biscoitos em excesso, diversas vezes, durante 0 período do plantão. 0 período de maior ocorrência destes fatos foi entre a meia-noite e três horas da manhã, horário em que ocorre um declínio do metabolismo orgânico. ${ }^{11}$

Apesar de este hábito alimentar não ser exclusividade dos trabalhadores do noturno, é relevante mencionar que faz parte dos recursos utilizados pelo trabalhador para manter-se acordado. Esses hábitos alimentares pouco nutritivos ocasionam um desequilíbrio na secreção e motilidade gastrointestinal, o que pode provocar pirose, transtornos de apetite, dificuldades de digestão, constipação, flatulência nos trabalhadores noturnos quando comparados ao do diurno. No entanto, ao analisar esses fatores, devem ser levados em conta fatores de confusão como idade, tabagismo, entre outras características individuais.

0 ganho ponderal também pode ser uma das consequências da impossibilidade da prática de atividade física, especialmente no dia posterior ao plantão noturno. Tal fato pode estar relacionado à influência do sono e do cansaçol desgaste físico e mental do trabalhador, como observado nos relatos:

[...] a alimentação não é controlada, observei ganho de peso [...] a atividade física é mais difíicil depois do plantão(E14).

[...] não consigo fazer exercício físico que eu gosto [...] não tenho nada fixo, um dia trabalho terça, quarta[...] não tem uma rotina para eu me organizar[...](E47).

A programação das atividades diárias deve privilegiar os horários mais compatíveis com o grau de alerta de cada tipo cronobiológico, almejando-se melhor desempenho e respeito à qualidade de vida das pessoas. Assim, por exemplo, o fato de dormir tarde e acordar mais tarde é preferido pelo cronotipo vesper tino; dormir cedo e acordar cedo é preferido pelos matutinos. ${ }^{12} \mathrm{~A}$ partir da determinação do cronotipo, podem ser projetadas medidas a serem adotadas no intuito de opor tunizar ao trabalhador a escolha do seu horário de trabalho.

Outra alteração percebida por seis enfermeiros foi 0 cansaço/desgaste. Além disso, foi observado nos relatos que alguns enfermeiros entendem que tudo o que ocorre 
após o plantão noturno faz parte do contexto, sendo considerado natural, esperado e aceito. Os depoimentos a seguir destacam que, apesar da interferência na saúde, 0 enfermeiro prefere trabalhar no noturno:

[...] a gente sente alterações. Alteração do sono, do humor, cansaço após o plantão [...] irritação coma família [...], mas ainda prefiro o noturno(E54).

[...] o que eu percebo é que no serviço noturno, aos poucos, tu vai cansando. Não é assim um ano, dois anos, quatro anos... veja bem, eu já estou há 12 anos no noturno [...] mas como eu gosto do noturno (risos) o cansaço é superável(E26).

A partir dos fragmentos, percebe-se que o enfermeiro banaliza o sofrimento quando diz que percebe as alterações no seu contexto de vida e na saúde, porém não atua para modificar essa situação. A forma de organização e a quantidade de tempo destinada ao trabalho assistencial hospitalar podem causar violência psicológica e ter efeito devastador e de longa duração na saúde dos trabalhadores. ${ }^{13}$

Além disso, os enfermeiros relataram que o trabalho no período noturno traz como consequência 0 isolamento e a dificuldade de participação em acontecimentos sociais e festejos comemorativos, conforme exemplificam os fragmentos:

[...] tem o lado negativo: festas é à noite! Às vezes a gente sai prejudicado, principalmente Natal e Ano Novo[...](E18).

[...] ]algumas festas são à noite, geralmente a gente procura pedir folga[ ...] mas é diferente porque 0 normal é estar em casa, anormal é tu sair! (E15).

[...]muitos compromissos com amigos, janta, aniversário[...] o convívio social, porque a maioria das pessoas trabalha durante o dia e a noite é 0 horário de se encontrar ..então, muitas vezes, eu não consigo par ticipar por causa disso (E47).

Com o trabalho noturno, fica difícil manter o ócio familiar e as relações sociais, 0 que faz com que muitos trabalhadores tenham a sensação de isolamento pois suas atividades não coincidem com as das pessoas que os cercam. A organização do trabalho de enfermagem deve utilizar meios para promover a sensibilização do trabalhador sobre estes fatos e adotar medidas para a proteção de sua saúde e da sua vida pessoal e profissional. ${ }^{3}$

As consequências na saúde do trabalhador decorrentes da realização do trabalho no período noturno se manifestam como alterações do equilibrio biológico, dos hábitos alimentares, do sono, da perda de atenção, da acumulação de erros, do estado de animo e da vida familiar e social. Essa particularidade requer atenção dos profissionais que têm a responsabilidade de dimensionar os recursos humanos em relação às atividades de enfermagem. ${ }^{14}$

Ao mesmo tempo em que os enfermeiros percebem as alterações na saúde decorrentes da realização do trabalho no período noturno e cer to isolamento com relação à sociedade, sete $(16,66 \%)$ fizeram referência à saída desse turno de trabalho. Assim, de um total de 42 enfermeiros entrevistados, $35(83,33 \%)$ expressaram o desejo em permanecer no serviço noturno e argumentaram que o serviço nesse turno possibilita continuar os estudos para aperfeiçoar conhecimentos, essencial para promover a qualidade da assistência; outros mencionaram o segundo emprego, e outros, o menor número de deslocamentos para o serviço:

[...] tenho outros planos, quero continuar os estudos(E14).

[...] tenho outro emprego durante o dia(E17).

[...] tenho necessidade de permanecer no noturno porque moro em outra cidade(E35).

Sobre as facilidades percebidas por enfermeiros para a realização do trabalho no noturno, cita-se 0 ambiente de trabalho mais tranquilo, melhor interação entre a equipe de enfermagem, maior disponibilidade de tempo para a vida particular, possibilidade de maior autonomia e de qualificação da assistência de enfermagem. ${ }^{15}$ Assim, por ser o trabalho noturno uma atividade inerente à profissão da enfermagem, principalmente no cenário hospitalar, entende-se que 0 trabalhador precisa considerar as demandas internas e externas para enfrentar tal atividade, bem como ter consciência dos cuidados necessários para se manter saudável.

Sobre o contexto da influência do trabalho noturno na vida pessoal do trabalhador, é preocupante o relato de um trabalhador que refere não conseguir se desligar do trabalho, tampouco dormir após o plantão noturno, conforme ilustra a fala a seguir:

[... ] a gente passa por situações bem estressantes! Então tu chega em casa e não consegue dormir, é muito apego, a gente sofre muito [...] tu vai para casa e depois acaba ligando e perguntado como 0 fulano está. Eu chego em casa e não consigo relaxar(E32).

0 relato preocupa na medida em que 0 trabalhador expressa um estado de alerta permanente. A diferenciação entre estado de alerta e o estado de alerta permanente é que no primeiro 0 trabalhador experimenta níveis de atenção $\mathrm{e}$ concentração elevados que, mediante a ocorrência de eventos críticos, faz emergir sinais e sintomas como sudorese, agitação 
e ansiedade; já no segundo, ocorre a manutenção desse estado mesmo quando o trabalhador está fora do ambiente de trabalho. Assim, um estado de alerta permanente, sem estratégias compatíveis de enfrentamento, parece contribuir para 0 adoecimento dos trabalhadores. ${ }^{16}$

\section{A título de reflexão}

Trabalhar no período noturno exige que o trabalhador conheça os limites físicos do seu corpo para que a realização da atividade não interfira no processo saúde-doença e, ao mesmo tempo, não comprometa a qualidade da assistência prestada.

Nesse contexto, entende-se necessário adotar medidas para reduzir o impacto na saúde e melhorar a segurança no trabalho dos trabalhadores do período noturno. Essas medidas constituem estratégias individuais e coletivas a serem instituídas a nível organizacional, como investir na melhoria das condições de trabalho, incluindo a boa iluminação, a orientação aos trabalhadores sobre as repercussões da realização do trabalho noturno em suas vidas e a implantação e incentivo aos trabalhadores da prática da ginástica laboral no ambiente de trabalho no intuito de colaborar com a saúde desses profissionais.

Também se sugere que os trabalhadores consumam alimentos mais leves nos plantões noturnos, evitem 0 açúcar em excesso e o consumo de alimentos fritos, restrinja o consumo de café e realizem atividades físicas de maneira sistemática, no intuito de minimizar as repercussões do trabalho em sua saúde.

Compete ao enfermeiro opinar, participar, decidir e intervir sobre a dimensão política, ${ }^{17}$ estabelecida pela capacidade de mobilizar grupos sociais de acordo com as demandas, necessidades e interesses da equipe. E para uma atuação mais efetiva é necessário reivindicar junto aos sindicatos melhorias nas condições de trabalho para a categoria da enfermagem no intuito de proporcionar saúde e qualidade de vida aos trabalhadores.

\section{CONSIDERAÇÕES}

Os enfermeiros que participaram deste estudo experimentam um conflito interno e externo: interno porque vão trabalhar no momento que o organismo se prepara para 0 descanso; externo porque há, por vezes, o isolamento social, uma vez que o trabalhador não consegue acompanhar a vida de relação social.

Por meio dos relatos, foi possivel identificar que, apesar da percepção das alterações na saúde decorrente da realização do serviço no noturno, poucos enfermeiros expressaramo desejo de trocar de turno de trabalho. E esse fator está diretamente relacionado ao desejo de continuar os estudos, ter outro emprego ou mesmo ao deslocamento para o trabalho.
0 trabalho noturno é considerado primordial para a continuidade da assistência de enfermagem. Nesse contexto, algumas reflexões sobre os dados encontrados neste estudo dizem respeito ao estudante da área da saúde, em especial ao graduando de enfermagem. Esse futuro profissional muitas vezes realiza plantões noturnos, no período letivo, no intuito de qualificar 0 aprendizado e adquirir experiência. É necessário conscientizá-lo sobre as repercussões da fadiga em associação à alternância do ciclo vigília-sono como a redução do estado de alerta, a dificuldade de concentração, a vulnerabilidade para a ocorrência de erros e acidentes de trabalho, entre outras repercussões.

É importante ressaltar que o tamanho da população e a subjetividade dos dados podem ser considerados um fator limitante deste estudo. Assim, sugerem-se novos estudos que investiguem a relação do trabalho noturno da enfermagem com a prática de atividade física no lazer, com a sonolência diurna e com o sobrepeso, na intenção de identificar possíveis relações e repercussões na saúde do trabalhador.

\section{REFERÊNCIAS}

1.Elias M, Navarro VL. A relação entre o trabalho, a saúde e as condições de vida: negatividade e positividade no trabalho das profissionais de enfermagem de um hospital escola. Rev Latino-am Enfermagem. 2006; 14(4): 517-25.

2.Lisboa MTL, Oliveira MM, Reis LD. 0 trabalho noturno e a prática de enfermagem: uma percepção dos estudantes de enfermagem. Esc Anna Nery. 2006; 10(3): 393-98.

3.Manhães VMS. Cronotipo e privação do sono nos trabalhadores do serviço noturno hospitalar de enfermagem [ dissertação]. Rio de Janeiro: Escola de Enfermagem Anna Nery, Universidade Federal do Rio de Janeiro; 2009.

4.Magalhães F, Maturana J. Sono. In: Jansen JM, et al. Medicina da noite. Rio de Janeiro: Fiocruz; 2007. p. 103-20.

5.Teixeira RC, Mantovani MF. Enfermeiros com doença crônica: as relações com 0 adoecimento, a prevenção e o processo de trabalho. Rev Esc Enferm USP. 2009; 43(2): 415-21.

6.Silva RM, Beck CLC, Guido LA, Lopes LFD, Santos JLG. Análise quantitativa da satisfação profissional dos enfermeiros que atuam no período noturno.Texto\& Contexto Enferm. 2009; 18(2): 298-305.

7.Minayo MCS. 0 desafio do conhecimento: pesquisa qualitativa em saúde. São Paulo: Hucitec; 2007.

8. Ministério da Saúde (BR). Conselho Nacional de Saúde. Resolução $n^{\circ}$ 196, de 10 de outubro de 1996. Diretrizes e normas regulamentadoras de pesquisas envolvendo seres humanos. Brasilia (DF); 1996 
8.Mauro MYC, Veiga AR. Problemas de saúde e riscos ocupacionais: percepções dos trabalhadores de enfermagem de uma unidade maternoinfantil. Rev Enferm UER). 2008; 16(1): 64-69.

9.Ferreira LRC, De Martino MMF. Stress no cotidiano de enfermagem. Estud Psicol. 2009; 26(1): 65-72.

10.0liveira MM. Alterações psicofisiológicas dos trabalhadores de enfermagem no serviço noturno [dissertação]. Rio de Janeiro: Universidade Estadual do Rio de Janeiro; 2005.

11.Alam MF, Tomasi E, Lima MS, Areas R, Menna Barreto L. Caracterização e distribuição de cronotipos no sul do Brasil: diferenças de gênero e estação de nascimento. J Bras Psiquiatr. 2008; 57(2): 83-90.

12. Costa ALRC, Marziale MHP. A relação tempo-violência no trabalho de enfermagem de urgência e emergência. Rev Bras Enferm. 2006; 59(3): 337-43.
13. Manhães VMS. Cronotipo e privação do sono nos trabalhadores do serviço noturno hospitalar de enfermagem [dissertação]. Rio de Janeiro: Univer sidade do Estado do Rio de Janeiro; 2009.

14.Silva RM, Beck CLC, Guido LA, Lautert L, Tavares JP, Prestes FC, et al. Night shift pros and cons in nursing: qualitative study. Online Braz J Nurs 2009, 8(2). [citado 2010 fev 04], Disponivel em: http://www.objnursing. uff.br/index.php/nursing/article/view/j.16764285.2009.2346.

15.Gonzales RMB, Beck CLC, Donaduzzi JC, Stekel LMC. O estado de aler ta: um estudo exploratório com o corpo de bombeiros. Esc Anna Nery. 2006; 10(3): 370-77.

17. Persegona KR, Rocha DLB, Lenardt MH, Zagonel IPS. 0 conhecimento político na atuação do enfermeiro. Esc Anna Nery. 2009; 13(3): 645-50. 